\title{
A modular magnetic anastomotic device for minimally invasive digestive anastomosis: proof of concept and preliminary data in the pig model
}

\author{
Michele Diana - Didier Mutter • Véronique Lindner • \\ Michel Vix · Hyunsoo Chung • Nicolas Demartines • \\ Jacques Marescaux
}

Received: 21 August 2013/Accepted: 28 November 2013/Published online: 3 January 2014

(C) Springer Science+Business Media New York 2014

\begin{abstract}
Background The aim of our study was to assess the feasibility of minimally invasive digestive anastomosis using a modular flexible magnetic anastomotic device made up of a set of two flexible chains of magnetic elements. The assembly possesses a non-deployed linear configuration which allows it to be introduced through a dedicated small-sized applicator into the bowel where it takes the deployed form. A centering suture allows the mating between the two parts to be controlled in order to include the viscerotomy between the two magnetic rings and the connected viscera.

Methods and procedures Eight pigs were involved in a 2-week survival experimental study. In five colorectal anastomoses, the proximal device was inserted by a percutaneous endoscopic technique, and the colon was divided below the magnet. The distal magnet was delivered
\end{abstract}

Presented at the 21st EAES Congress, June 19-22, 2013, Vienna, Austria.

Electronic supplementary material The online version of this article (doi:10.1007/s00464-013-3360-2) contains supplementary material, which is available to authorized users.

M. Diana ( $)$ - D. Mutter · M. Vix · H. Chung · J. Marescaux Department of General, Digestive and Endocrine Surgery, IRCAD-IHU, University of Strasbourg, 1, Place de l'Hôpital, 67091 Strasbourg, France

e-mail: michele.diana@ircad.fr

M. Diana $\cdot$ N. Demartines

Department of Visceral Surgery, CHUV, University Hospital of Lausanne, Rue du Bugnon 46, 1005 Lausanne, Switzerland

V. Lindner

Department of Pathology, Hospital of Mulhouse, Mulhouse, France transanally to connect with the proximal magnet. In three jejunojejunostomies, the first magnetic chain was injected in its linear configuration through a small enterotomy. Once delivered, the device self-assembled into a ring shape. A second magnet was injected more distally through the same port. The centering sutures were tied together extracorporeally and, using a knot pusher, magnets were connected. Ex vivo strain testing to determine the compression force delivered by the magnetic device, burst pressure of the anastomosis, and histology were performed. Results Mean operative time including endoscopy was $69.2 \pm 21.9 \mathrm{~min}$, and average time to full patency was 5 days for colorectal anastomosis. Operative times for jejunojejunostomies were 125,80 , and 35 min, respectively. The postoperative period was uneventful. Burst pressure of all anastomoses was $\geq 110 \mathrm{mmHg}$. Mean strain force to detach the devices was $6.1 \pm 0.98$ and $12.88 \pm 1.34 \mathrm{~N}$ in colorectal and jejunojejunal connections, respectively. Pathology showed a mild-to-moderate inflammation score. Conclusions The modular magnetic system showed enormous potential to create minimally invasive digestive anastomoses, and may represent an alternative to stapled anastomoses, being easy to deliver, effective, and low cost.

Keywords Magnetic anastomosis - Compression anastomosis - Sutureless anastomosis - Modular AutoAssembling Magnetic Anastomotic System .

MAGNAMOSIS $^{\circledR}$. Minimally invasive digestive surgery · Flexible anastomotic system

The introduction of mechanical staplers (linear and circular) has enabled complex minimally invasive laparoscopic procedures such as colorectal resection or bariatric procedures. However, the design of the circular stapler (rigid 
body, limited length, and diameter ranging from 2.5 to $3.5 \mathrm{~cm}$ ) does not allow the anastomosis to be performed beyond the rectum, and the anvil's introduction at the proximal resection site requires a mini-laparotomy or some tricky artifices such as Natural Orifice Specimen Extraction [1-4]. At the same time, performing a minimally invasive laparoscopic side-to-side jejunojejunostomy using the linear stapler requires extensive training in suturing in order to close enterotomies, as well as extra operative time. To overcome these limits, new technologies such as mechanical staplers mounted on the shaft of a flexible endoscope [5], or anastomotic devices that can be directly applied in the intestinal lumen through an endoscopic or percutaneous delivery are required.

Compression-based sutureless anastomosis of hollow viscus is based on the natural process of tissue remodeling and healing. A constant pressure is exerted on the apposed walls of two visceral segments by some specific devices leading to transmural ischemia, necrosis, and scarring with, finally, full-thickness soldering of the connected segments within a few days. This concept was initially proposed almost two centuries ago, in 1826, by Felix-Nicholas Denans who used a metallic ring to perform an end-to-end anastomosis in a canine model [6]. In 1892, an evolution of Denans' ring, Murphy's button, composed of metal rings that are screwed together across tissues, was developed [711]. After a long discontinued period, the concept of sutureless compression-based anastomosis was revisited in the early 1980s, with the initial human experiences with magnetic compression anastomoses, when Jansen et al. reported five cases of colonic resections in which a couple of magnetic rings were used to achieve a compressionbased mucosa-to-mucosa anastomosis while the outer serosal layer was hand-sewn [12].

The MAGNAMOSIS ${ }^{\circledR}$ (or Harrison's rings) is a recently developed system for compression-based anastomoses comprised of two self-aligning magnetic rings. The MAGNAMOSIS ${ }^{\circledR}$ can create reliable, full-thickness, smallbowel anastomoses [13-15]. At our institute, the MAGNAMOSIS $^{\circledR}$ has been tested in the animal model for image-guided procedures using endoscopic delivery of magnets, as well as for hybrid or pure Natural Orifice Transluminal Endoscopic Surgery (NOTES) colectomies [16-18]. The limitations experienced with the MAGNAMOSIS ${ }^{\circledR}$ system are mainly related to the rigid aspect of the device and its $2.5 \mathrm{~cm}$ diameter, requiring quite a large enterotomy to be inserted into the small bowel as well as extra operative time to close it.

In 2011, Ryou et al. [19] proposed the Smart SelfAssembling MagnetS for ENdoscopy (SAMSEN), an endoscopically delivered magnetic anastomotic device with a linear delivery configuration fitting an endoscopic channel and a self-deploying rectangle-shaped in-site configuration.
The authors performed totally NOTES gastrojejunostomies in five acute pigs under fluoroscopic guidance.

At the same time, at our institute, a Modular AutoAssembling Anastomotic System made up of a set of two flexible chains of magnetic elements was under development. The assembly shares some of the properties of the SAMSEN since it possesses a non-deployed linear configuration, which allows it to be introduced through a dedicated small-sized applicator ( $8 \mathrm{~mm}$ in diameter) into the bowel where it takes the deployed form. A centering suture connecting the ring to the center allows the mating between the two parts to be controlled in order to include the viscerotomy between the two magnetic rings and the connected viscera. The aim of this study was to assess the feasibility of minimally invasive digestive anastomosis using this novel, modular, flexible, magnetic anastomotic device in the porcine model.

\section{Materials and methods}

This feasibility study protocol was approved by the local Ethics Committee, and animals were managed in accordance with French laws for animal use and care, as well as with the European Community Council directive No. 86/609/EEC.

\section{Animals}

Eight pigs (Sus scrofa domesticus, large white subspecies; male/female $=7 / 1$; weighing $35-40 \mathrm{~kg}$ ) were included in the study. Five pigs underwent a hybrid laparoendoscopic sigmoid resection with magnetic anastomosis, and three pigs underwent laparoscopic jejunojejunostomy with magnetic anastomosis. Animals were fasted for $24 \mathrm{~h}$ prior to the procedure, with free access to water. Ketamine $(7 \mathrm{ml})$ and azaperone (3 ml, Stresnil; Janssen-Cilag, Beerse, Belgium) were administered intramuscularly $1 \mathrm{~h}$ before the procedure as premedication. Induction of anesthesia was achieved using intravenous propofol combined with pancuronium $(2 \mathrm{ml})$. Anesthesia was maintained with $2 \%$ isoflurane after endotracheal intubation of the animal lying supine. A rectal cleansing was performed until the effluent turned clear. Postoperative antibiotic prophylaxis (cefazolin sodium; $10 \mathrm{mg} / \mathrm{kg}$ ) was administered for 5 days. Pigs were housed in separate cages, fasted on the night of surgery, and given regular diet on postoperative day (POD) 1 .

Manufacturing of the custom-made modular magnetic anastomotic system and the delivery kit

The modular, flexible, magnetic anastomotic device is made up of a set of two flexible chains of magnetic elements made 

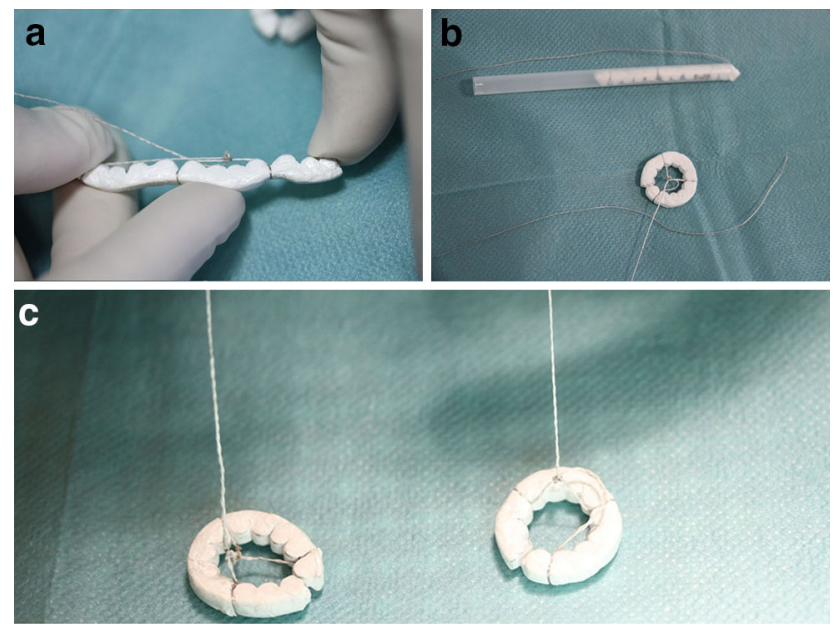

Fig. 1 Modular Auto-Assembling Anastomotic System. The modular magnetic anastomotic device used in this study is made up of a set of two flexible chains of magnetic elements made of Neodymium Iron Boron, which were fixed internally to an open plastic ring using a Teflon ${ }^{\circledR}$ tape. The assembly possesses a forced non-deployed linear configuration (A) which is held in a Teflon ${ }^{\circledR}$ catheter (B), and a deployed circular configuration $(\mathbf{C})$

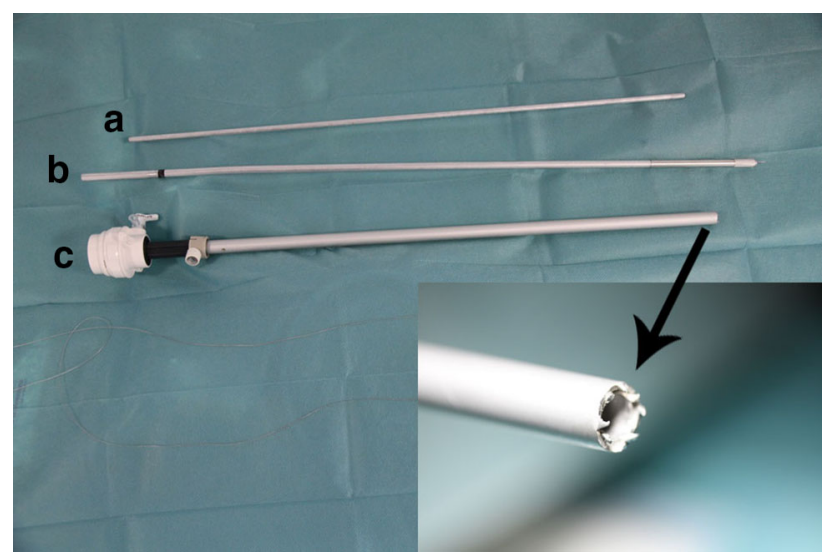

Fig. 2 Custom-made delivery kit. The delivery kit was composed of a metal non-ferromagnetic tube equipped with 'twisting teeth' at the tip, designed to grasp and secure the bowel, which is directly inserted through a $10-\mathrm{mm}$ port $(\mathbf{C})$. The magnet is loaded in its linear position into a Teflon ${ }^{\circledR}$ tube, and is pushed out using a non-ferromagnetic shaft (A). If required, a blade mounted on a long shaft (B) could be used to enlarge the enterotomy directly through the tube $(\mathbf{C})$. The arrow shows the detail of the twisting teeth of the grasping tube

of neodymium iron boron (NdFeB). In this feasibility study, a custom-made prototype was used in which the cylindrical magnetic elements composing the chain were fixed internally to an open plastic ring using a Teflon ${ }^{\circledR}$ tape. Each cylindrical magnet was $5 \mathrm{~mm}$ high and $4 \mathrm{~mm}$ in diameter. The assembly possesses a non-deployed linear configuration which allows it to be introduced through a dedicated smallsized applicator ( $8 \mathrm{~mm}$ in diameter) into the bowel where it takes the deployed form. The diameter of the deployed device was $2.5 \mathrm{~cm}$ in diameter. A centering suture connecting the ring to the center allows the mating between the two parts to be controlled to include the viscerotomy between the two magnetic rings and the connected viscera (Fig. 1). The custom-made delivery kit was composed of a metal non-ferromagnetic tube equipped with 'twisting teeth' at the tip, designed to grasp and secure the bowel, which is directly inserted through a $10 \mathrm{~mm}$ port. The magnet is loaded in its linear position into a Teflon ${ }^{\circledR}$ tube, with a smooth bevel-tip, which in turn can be inserted through the metal tube. The magnet can be pushed out through the Teflon ${ }^{\circledR}$ tube by pushing it with a non-ferromagnetic shaft inserted from the outer side (Fig. 2).

\section{Procedures}

\section{Colorectal anastomosis $(n=5)$ (video clip 1$)$}

The pneumoperitoneum was established using a Veress needle, and three ports (Covidien, Norwalk, CT, USA) were inserted. The pig was placed in a steep Trendelenburg position. A window was created in the sigmoid mesentery using the LigaSure ${ }^{\mathrm{TM}}$ Advance $^{\mathrm{TM}}$ (Covidien, Boulder, CO, USA) vessel-sealing device. The first modular magnetic ring was positioned at the proximal resection site of the sigmoid colon using a percutaneous endoscopic PEG-like approach [20]: the sigmoid wall was punctured with a needle and a guidewire (Bavarian Wire; Medi-Globe, Achenmühle, Germany) was inserted through the needle and grasped by an endoscope (Karl Storz, Tuttlingen, Germany). The guidewire was pulled outside the anus and the centering suture of the magnetic ring was attached to the guidewire. By pulling on the percutaneous guidewire, the magnet was precisely placed at the chosen proximal site. The sigmoid colon was transected below the magnet using an EndoGIA ${ }^{\mathrm{TM}}$ linear stapler (Covidien, Norwalk, CT, USA). No colonic resection was performed. The rectal stump was perforated using the electrocautery tip of the LigaSure $^{\mathrm{TM}}$ vessel-sealing system, which was introduced into the rectum through a plastic overtube. The LigaSure ${ }^{\mathrm{TM}}$ system was then introduced into the abdominal cavity through the small transrectal viscerotomy and used to grasp the centering suture of the proximal magnetic ring, which was pulled out at the anus. The distal magnet was pushed transanally to the upper rectum using the centering suture as a guide and a plastic tube until magnets joined under laparoscopic control. After the initial experiences, nonferromagnetic, single-use laparoscopic instruments (VECTEC $^{\mathrm{TM}}$, Vichy, France) were preferred over standard instruments to facilitate magnet manipulation. When required (i.e. in case of poor alignment between the sigmoid and the rectal enterotomy at the center of magnetic rings), the interposed tissue within the inner ring of the magnets was cut endoscopically using a needle knife 

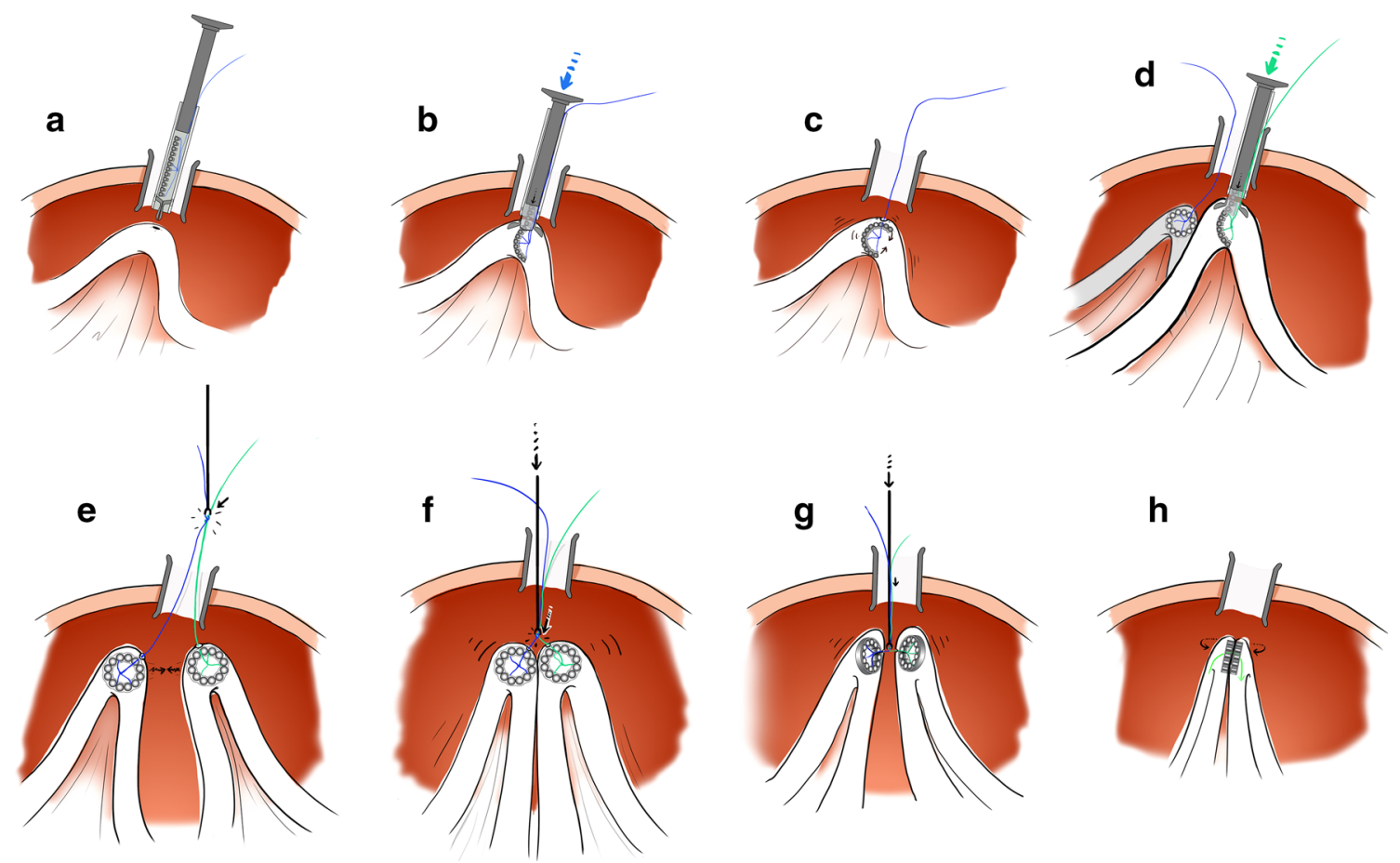

Fig. 3 Modular Auto-Assembling Magnetic Anastomotic System technique used to perform jejunojejunostomies. (A) A small enterotomy is created in the small bowel, and (B) a grasping tube is introduced through the port to secure the small bowel and allow delivery of the first magnetic chain; (C) the magnetic chain has been injected in its linear configuration through the tube inserted into the bowel by pushing with a non-ferromagnetic shaft, and once totally

(Boston Scientific, Spencer, IN, USA), creating immediate patency.

\section{Jejunojejunal anastomosis $(n=3)$ (video clip 2 and Fig. 3)}

A three-port approach was used. A first jejunal loop was identified and anchored to the anterior surface of the stomach with a stay suture. The custom-made grasping tube was introduced through the $10 \mathrm{~mm}$ port to secure the small bowel and allow the delivery of the first magnetic chain. A small enterotomy was created introducing a steel blade mounted on a long shaft through the grasping tube. The magnetic chain was introduced at the tip of an $8 \mathrm{~mm}$ Teflon ${ }^{\circledR}$ tube equipped with a bespoke bevel to facilitate introduction through the enterotomy. The self-assembling magnetic chain was injected in its linear configuration through the tube inserted into the bowel by pushing with a non-ferromagnetic shaft. Once totally delivered in the bowel lumen, the device selfassembled into a ring shape. Subsequently, the second part of the device was injected into a more distal $(100 \mathrm{~cm})$ loop through the same port. The two centering sutures were tied together extracorporeally. By pulling on the sutures and using a knot pusher, magnets were connected.

delivered in the bowel lumen, the device self-assembled into a ring shape; (D) the second part of the device is injected into a second bowel loop through the same port system; (E) the two centering sutures are tied together extracorporeally; (F) by pulling on the sutures and using a pushing knot, (G) magnetic rings are connected and enterotomies are aligned and covered by the magnets

\section{Outcomes}

\section{Clinical}

General clinical conditions, eating behavior, bowel movements, and passage of magnets were monitored twice a day by both a physician and the person responsible for the laboratory animal facility.

\section{Endoscopy}

On POD 7 and POD 14, animals from the colorectal anastomosis group underwent a surveillance endoscopy to evaluate the anastomotic site to control patency and rule out stenosis. A conventional $11 \mathrm{~mm}$ diameter endoscope (Karl Storz, Tuttlingen, Germany) was used. Stenosis was defined as follows: $0=$ no stenosis; $1=$ endoscope can be passed; 2 = endoscope cannot be passed.

\section{Laparotomy}

On POD 14, pigs underwent control laparotomy to assess intra-abdominal adhesions, anastomotic dehiscence, and infectious complications (abscesses, peritonitis). Adhesions 
Fig. 4 Burst pressure setting. The closed section of the specimen including the anastomosis was cannulated with two $18 \mathrm{~g}$ needles. One needle was connected to a pressure transducer of the anesthesia unit and the other to a syringe filled with a mixture of saline and betadine (povidoneiodine). The specimen was injected gradually and the maximum pressure displayed on the screen prior to rupture was recorded
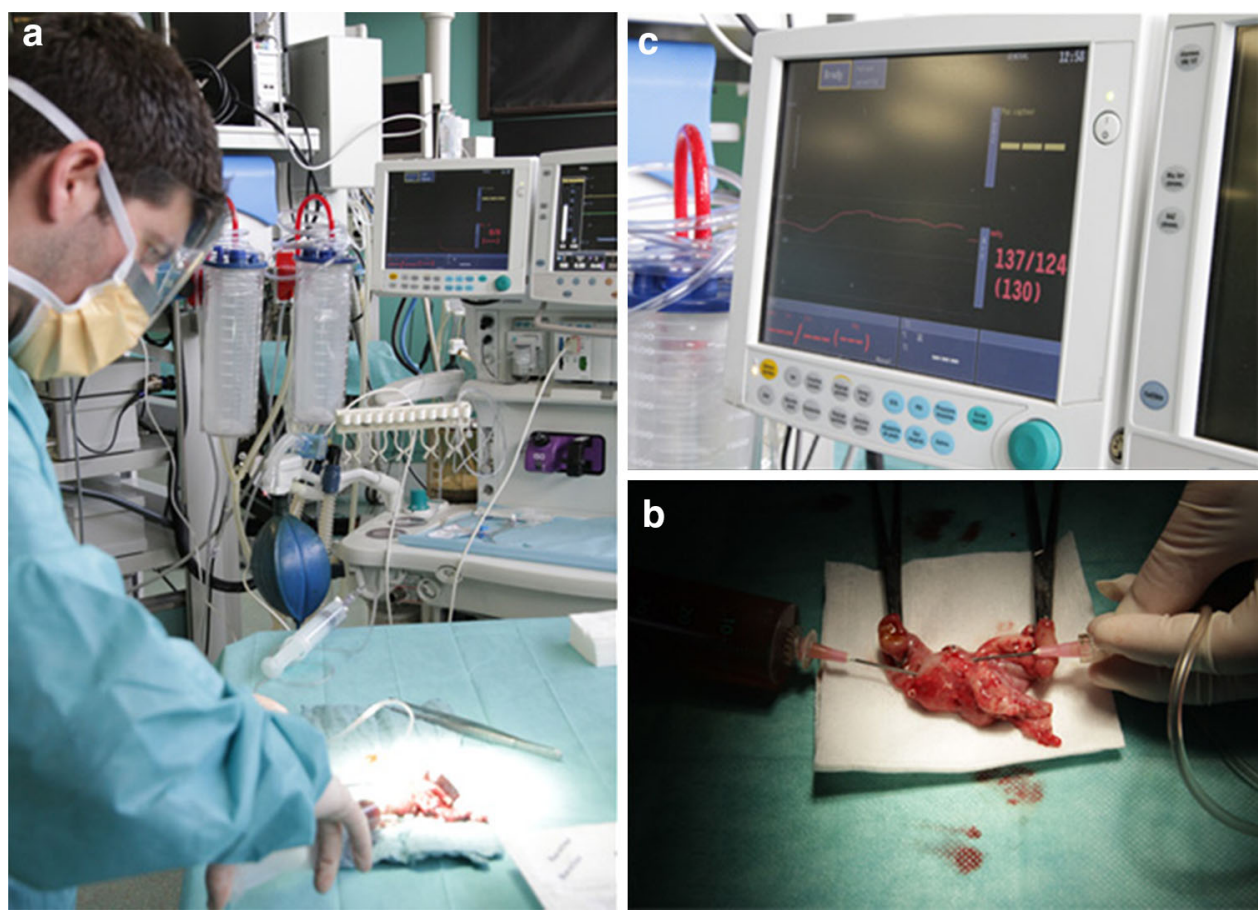

were graded as follows: no adhesions $=0$; tiny and easy to separate $=1$; thick and firm $=2$. At the end of the procedure, a sigmoidectomy (in the colorectal anastomosis group) and a bowel resection (jejunojejunal group) were performed to retrieve the intact surgical specimen. including the anastomosis.

\section{Burst pressure}

Specimens were resected using EndoGIA ${ }^{\mathrm{TM}}$ linear staplers (Covidien, Norwalk, CT, USA) approximately $5 \mathrm{~cm}$ above and below the magnetic anastomosis. The closed section of the bowel including the anastomosis was cannulated with two $18 \mathrm{~g}$ needles. One needle was connected to a pressure transducer of the anesthesia unit and the other to a syringe filled with a mixture of saline and betadine (povidoneiodine). The specimen was injected gradually and maximum pressure prior to rupture was recorded (Fig. 4).

\section{Strain test to characterize the magnetic compression}

After bursting the specimens, a segment of bowel close to the anastomotic site was cut and used to perform ex vivo strain testing. The magnet was placed inside one resected bowel segment, which was fixed at four cardinal points with sutures to the hook of a digital force gauge (Chatillon DFS 0200; Ametek, Elancourt, France). A second bowel segment housing the other magnet was placed in magnetic contact with the first one. The segments were separated by manual vertical pulling and the maximum force required to separate magnets was recorded. This force was assumed to reflect the compression force exerted by the magnetic rings with interposed tissue. Each test was performed in each animal using the same set of magnets that generated the anastomosis in that specific animal, and that were regained during follow-up or intraoperatively during explorative laparotomy.

\section{Pathology}

Specimens were fixed in $4 \%$ buffered formalin for at least $24 \mathrm{~h}$. Macroscopic evaluation was performed by an independent pathologist, after longitudinal specimen opening to assess the diameter of the anastomosis and to compare it to the mean diameters of the sections above and below the anastomotic site. Additionally, adhesions at the serosa site were also evaluated. Microscopic evaluations were made on $4 \mu \mathrm{m}$ sections cut from paraffin-embedded tissues and stained with hematoxylin-eosin. Six sections per anastomosis were analyzed. Assessments were made for the presence of fibroblasts, polynuclear neutrophils, lymphocytes, and macrophagic cells. A semi-quantitative scoring system was used to assess inflammation, fibrosis, and vascularization. The severity of histological changes were scored using the following system: $0=$ absent; 1 $(1-30 \%)=$ mild; $\quad 2 \quad(31-60 \%)=$ moderate; $\quad 3$ $(>60 \%)=$ severe. Histological changes evaluated were as follows: (a) ulceration, defined as replacement of the epithelial layer by the inflammatory reaction; (b) fibrosis, defined as replacement of the epithelial layer by fibroblasts; 


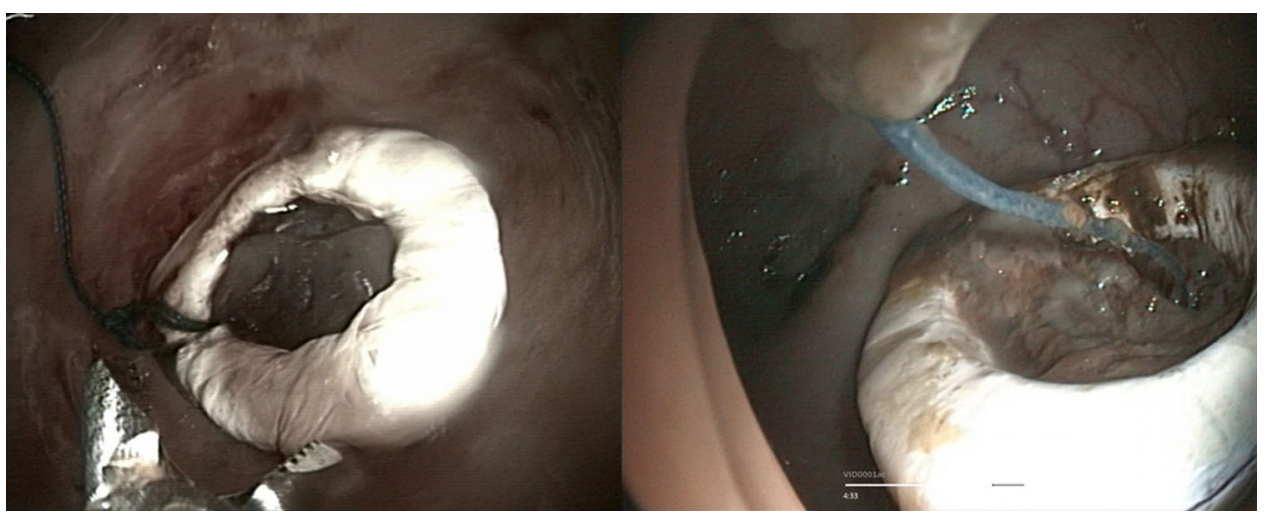

Fig. 5 Endoscopic aspect of the magnetic anastomotic device. In two of five colorectal cases, the 'proximal and distal holes' included in the magnetic rings, as a result of the percutaneous puncture made to introduce the proximal magnet and the transrectal viscerotomy for the distal magnet, were not sufficiently large to allow for satisfactory gas evacuation so that a 'blow hole' was created by cutting the tissue within the rings using a needle-knife
Fig. 6 Endoscopic aspect of the colonic anastomosis at 2 -weeks of follow-up. Postoperative day 14 endoscopy showing a wellhealed anastomosis with a delicate fibrotic lining witnessing the sealing of connected segments between magnets

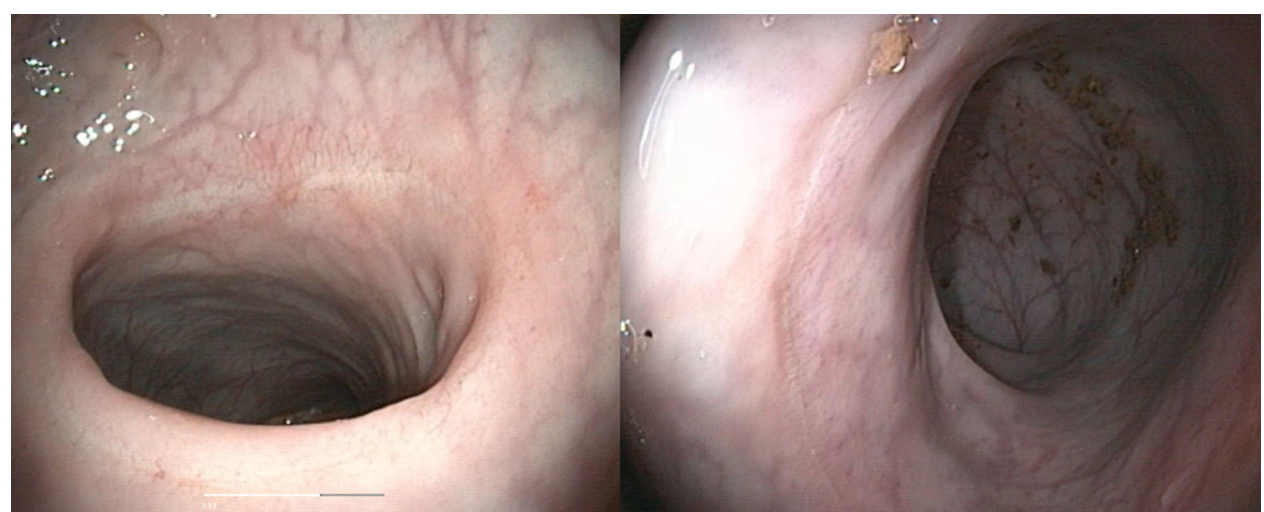

and (c) adhesions, defined as irregular and hypervascular fibrosis overlying the serosa.

\section{Statistical analysis}

Statistics were performed using the GraphPad Prism 5 software. A $t$ test was used to calculate $p$ values for quantitative variables. A Chi-squared test was used to calculate $p$ values for categorical variables, and a $p$ value $<0.05$ was considered statistically significant.

\section{Results}

\section{Procedures}

Mean operative time including endoscopy was $69.2 \mathrm{~min}$ (SD 21.9) for colorectal anastomosis, and 125, 80, and $35 \mathrm{~min}$ for the three small-bowel anastomoses, respectively. The Modular Auto-Assembling Anastomosis System was easily deployed and safely placed in all cases. In two of five colorectal cases, the percutaneous punctures made to introduce the proximal magnet and the transrectal viscerotomy at the center of the distal magnet were deemed insufficiently large and not perfectly aligned to allow satisfactory gas evacuation. The objective was to create a hole by cutting the tissue with a needle-knife (Fig. 5). The use of non-ferromagnetic instruments greatly facilitated the manipulation of magnets. In cases of non-perfect alignment between the magnetic chains, only a very small amount of force was required to reposition and lock them in total opposition.

\section{Clinical follow-up}

The postoperative period was uneventful. One pig did not gain weight but no complications were noticed at the 2-week necropsy, and the anastomosis was fully patent. Average time to full patency (elimination of magnets) was 5 days for colorectal anastomosis. With regard to jejunojejunostomies, in one case magnets were expelled after 12 days, and in two cases, magnets were found in the caecum at explorative laparotomy. 


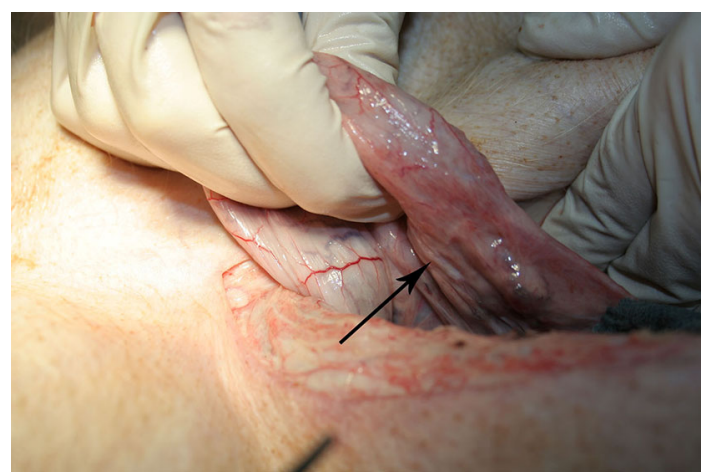

Fig. 7 Serosal aspect of the anastomosis. An example of a nicely healed magnetic colonic anastomosis with a barely visible fibrotic ring on the serosa at the explorative laparotomy

\section{Endoscopy}

At control endoscopies, there was no stenosis of colorectal anastomosis. POD 14 endoscopy showed a well-healed anastomosis with a delicate and barely visible fibrotic lining witnessing the sealing of connected segments between magnets (Fig. 6).

\section{Laparotomy}

There were no abscesses or fluid collections in all cases. Firm adhesions were present in two of five colorectal anastomoses, and in two of three jejunojejunostomies. No adhesions were found in the remaining cases (Fig. 7).

\section{Burst pressure}

Burst pressure of all anastomoses was greater than $110 \mathrm{mmHg}$. Mean burst pressure for colorectal anastomosis was $124 \mathrm{mmHg}$ (SD 11.91), and $153.66 \mathrm{mmHg}$ (SD 41.04) for jejunojejunostomies.

\section{Strain test}

Mean strain force to detach the devices was $6.1 \mathrm{~N}$ (SD $0.98)$ and $12.88 \mathrm{~N}$ (SD 1.34) in colorectal and jejunojejunal connections, respectively $(p=0.035)$. There was no significant correlation between magnetic force exerted by magnets and burst pressure $\left(R^{2}=0.43\right)$ of all specimens (Fig. 8).

\section{Pathology}

Pathology showed that all anastomoses were sealed. At macroscopic analysis, the median percentage of diameter reduction at the anastomotic site was $20.5 \%$ (range 0-35) when compared with the proximal and distal bowel diameter. The mean adhesion score at the serosa site was 2 (moderate). In two cases, there were adhesions with other organs (e.g. bladder in two colorectal anastomoses). At microscopic analysis, the mean global inflammation score was 2 (moderate) for colorectal anastomosis and 1 (mild) for jejunojejunostomies, with a prevalence of acute inflammatory changes at the mucosa/submucosa and chronic changes at the serosa site (Table 1).

\section{Discussion}

For almost two centuries, digestive surgeons have searched for the optimal anastomotic technique [21], ensuring sufficient blood supply, optimal serosa apposition, and no tension on the anastomotic site [22].

These elements are key factors to reduce the risk of leakage and/or stenosis, which are the most frequent postoperative anastomotic complications, with relevant morbidity and mortality. The reported rate of anastomotic leakage ranges from 1-24\% [23-25], while anastomotic strictures complicate colorectal surgery in 3-30\% of cases,
Fig. 8 Relationship between magnetic force and burst pressure. No significant correlation between magnetic force exerted by magnets and burst pressure $\left(R^{2}=0.4399\right)$ of all specimens was found

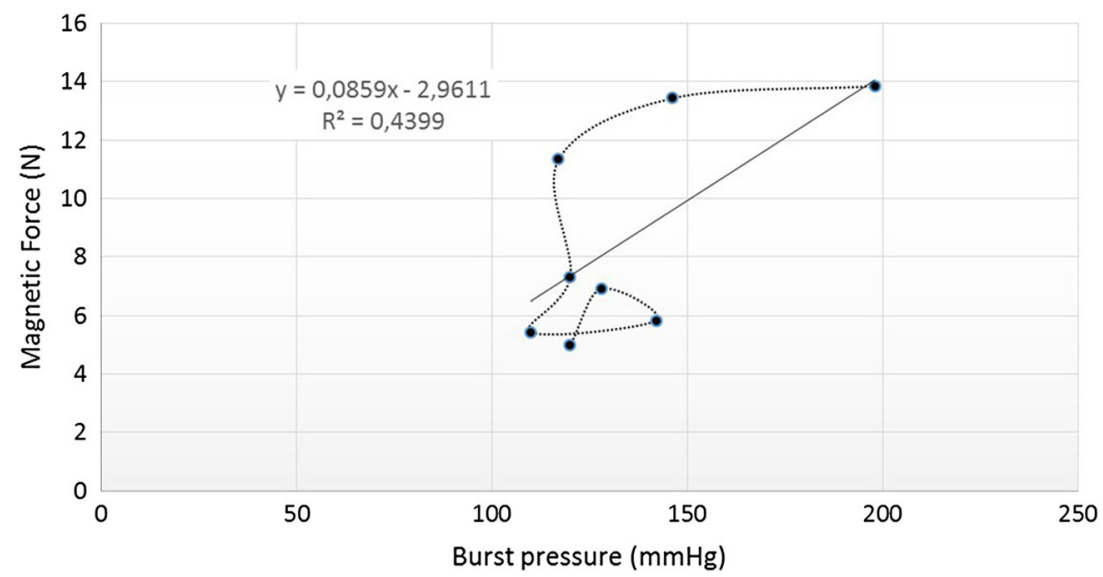


Table 1 Histology of colorectal anastomosis and jejunojejunostomies

\begin{tabular}{|c|c|c|c|c|c|c|c|c|c|c|c|c|}
\hline & \multirow[t]{2}{*}{$N$} & \multirow{2}{*}{$\begin{array}{l}\text { Inflammation } \\
\text { Overall } \\
\text { (score) }\end{array}$} & \multicolumn{3}{|c|}{ Mucosa/submucosa } & \multicolumn{3}{|c|}{ Muscularis } & \multicolumn{4}{|l|}{ Serosa } \\
\hline & & & $\begin{array}{l}\text { Acute } \\
(\% \\
\text { PMN })\end{array}$ & $\begin{array}{l}\text { Chronic } \\
\text { (\% L; } \\
\text { Mo; } \\
\text { Macro) }\end{array}$ & $\begin{array}{l}\text { Fibrosis } \\
\text { (score) }\end{array}$ & $\begin{array}{l}\text { Acute } \\
(\% \\
\text { PMN })\end{array}$ & $\begin{array}{l}\text { Chronic } \\
\text { (\% L; } \\
\text { Mo; } \\
\text { Macro })\end{array}$ & Fibrosis & $\begin{array}{l}\text { Acute } \\
(\% \\
\text { PMN })\end{array}$ & $\begin{array}{l}\text { Chronic } \\
\text { (\% L; } \\
\text { Mo; } \\
\text { Macro })\end{array}$ & $\begin{array}{l}\text { Fibrosis } \\
\text { (score) }\end{array}$ & $\begin{array}{l}\text { Vasc. } \\
\text { (score) }\end{array}$ \\
\hline \multirow[t]{5}{*}{$\begin{array}{l}\text { Colorectal } \\
\text { anastomosis }\end{array}$} & 1 & 2 & 30 & $\begin{array}{r}60 ; 0 \\
\quad<10\end{array}$ & 0 & 0 & $90 ; 0 ; 10$ & 1 & 0 & $100 ; 0 ; 0$ & 2 & 3 \\
\hline & 2 & 1 & 0 & $\begin{array}{c}20 ; 10 \\
70\end{array}$ & 1 & 0 & $90 ; 0 ; 10$ & 2 & 0 & $100 ; 0 ; 0$ & 2 & 2 \\
\hline & 3 & 3 & 80 & $\begin{array}{c}20 ;<1 \\
\quad<1\end{array}$ & 1 & 0 & $\begin{array}{c}40 ; 50 \\
10\end{array}$ & 1 & 0 & $\begin{array}{c}20 ; 80 \\
\quad<1\end{array}$ & 2 & 3 \\
\hline & 4 & 2 & 50 & $40 ; 0 ; 10$ & 1 & 50 & $10 ; 0 ; 40$ & 1 & 0 & $60 ; 40 ; 0$ & 2 & 1 \\
\hline & 5 & $0 / 1$ & $<5$ & $60 ; 0 ; 35$ & 1 & 0 & $80 ; 0 ; 20$ & 1 & 0 & $100 ; 0 ; 0$ & 1 & 2 \\
\hline \multirow[t]{3}{*}{ Jejunojejunostomy } & 1 & 1 & 0 & $0 ; 0 ; 0$ & 0 & 0 & $70 ; 30 ; 0$ & 1 & 20 & $40 ; 0 ; 40$ & 2 & 2 \\
\hline & 2 & 2 & 70 & $20 ; 0 ; 10$ & 1 & 5 & $40 ; 0 ; 60$ & 2 & 0 & $100 ; 0 ; 0$ & 2 & 2 \\
\hline & 3 & $0 / 1$ & 0 & $0 ; 0 ; 0$ & 0 & 0 & $\begin{array}{l}50 ; 40 \\
10\end{array}$ & 0 & 0 & $100 ; 0 ; 0$ & 1 & 1 \\
\hline
\end{tabular}

Score $0=$ absent, $1(1-30 \%)=$ mild, $2(31-60 \%)=$ moderate, $3(>60 \%)=$ severe

$P M N$ polymorphonuclear leukocytes, $L$ lymphocytes, Mo monocytes, Macro macrophages, Vasc vascularization of fibrosis

and bariatric surgery (gastrojejunal anastomosis related to Roux-en-Y gastric bypass) in 3-27\% of cases [26].

The process of anastomotic healing is complex and multifactorial, and depends on the patient's cardiovascular and metabolic status as well as on surgical technique. The impact of the technique itself has been largely investigated [11]. Manual suturing and mechanical stapling remain the most popular anastomotic techniques in daily practice. Stapled anastomosis heals with minimal inflammatory response when compared with manual anastomosis [27, 28]. However, regarding leak rate and stenosis rate, current evidence is scarce to demonstrate any superiority of either technique [29], and both methods involve foreign materials, sutures, or metallic staples, remaining in the body to perform the anastomosis.

Long before the introduction of mechanical staplers, the creation of anastomosis by applying a constant and more or less controlled compression across two approximated viscera was developed by Felix-Nicholas Denans in 1826 with the introduction of Denans' ring [6], and later on in 1892, by Murphy with his 'button', composed of metal rings that are screwed together across tissues [7-11].

The first experiences with magnetic compression anastomoses date back to more than 30 years ago [12]. Multiple subsequent studies have shown the feasibility and safety of compression-based magnetic anastomosis using flat circular or rectangular-shaped magnets [30-33]. However, magnetic-based anastomoses have failed to gain popularity so far. This might be due to some limitations of devices available, mainly in what concerns the delivery system to the target site, optimal compression force, and the ability to produce an immediately patent anastomosis.

Our Modular Auto-Assembling Anastomosis System (IRCAD-IHU, Strasbourg, France) falls within the quest to optimize and adapt the magnetic anastomotic concept to minimally invasive surgery. The main endpoint was to improve the delivery process, designing a self-assembling device able to pass from a relatively thin (height $0.6-0.8 \mathrm{~cm}$ ) linear non-deployed configuration to a circular assembled structure, without compromising the ability to obtain compression-based anastomoses.

The Modular Auto-Assembling Anastomotic System can be delivered percutaneously through a $10 \mathrm{~mm}$ laparoscopic port site and an $8 \mathrm{~mm}$ dedicated catheter. For that purpose, a very small enterotomy is required and the future anastomotic site can be precisely determined under laparoscopic guidance. This delivery is mostly suited for minimally invasive jejunojejunostomies, e.g. in the case of a Roux-enY gastric bypass (RYGB), and centering sutures allow for a perfect overlapping of the 'cutting parts' of magnets to include enterotomies. In this preliminary study, we could easily perform these steps. After the first experience with standard instruments, we could dramatically reduce the operative time by using non-ferromagnetic instruments to manipulate the magnetic device. Alternatively, for colonic resections or gastrojejunostomies, one of the magnets can be introduced endoscopically directly through natural orifices (e.g. anus, mouth) in its circular form, while the second is introduced percutaneously at the corresponding proximal anastomotic site or in the jejunal loop. 
Improvement in the delivery process with our modular device seems quite obvious, at least for jejunojejunostomies, when compared with circular rigid magnetic anastomotic systems, such as the MAGNAMOSIS ${ }^{\circledR}$. In previous experiences with the MAGNAMOSIS ${ }^{\circledR}$, we could show that combining hybrid laparoendoscopic techniques may allow for virtually any digestive anastomoses $[16,18]$. However, the rigid aspect of the magnetic device and the relatively large diameter (up to $2.3 \mathrm{~cm}$ ) would require a very large surgical access to be introduced into the peritoneal cavity and it would necessitate a large enterotomy to be inserted into the small bowel as well as extra operative time to close it. For that reason, at least for minimally invasive jejunojejunostomies, there is no scientific need to assess the superiority of the delivery system in a study comparing some fixed versus a self-assembling device.

The other crucial point is to verify whether the selfassembling feature compromises performances. Optimal compression force is, in fact, crucial to ensure a gradual healing process and produce a minimal inflammatory reaction while keeping a sufficiently strong connection to avoid displacement.

The magnetic elements forming the custom-made IRCAD flexible prototype are placed alternatively in a positive-negative sequence. This configuration presents a global magnetic force, which is slightly inferior to the one achievable with the same magnetic mass, but has the advantage of having a 'locked' position, i.e. when all polarities meet the opposite polarities on the second magnet. Without this perfect alignment of the magnetic couple, i.e. if the locked position is not reached, it is very easy to detach an improperly connected device.

The device used in this preliminary study had a mean 'wet' (i.e. with interposed tissue) force of $622.02 \mathrm{~g}(6.1 \mathrm{~N})$ in colorectal and $1,313.39 \mathrm{~g}(12.88 \mathrm{~N})$ in jejunojejunal connections, respectively. The compression force in colorectal anastomoses was comparable to those found using the MAGNAMOSIS ${ }^{\circledR}$ in a previous study performed at our institute [18], despite the smaller magnetic mass.

As a comparison, the magnets of the SAMSEN could generate an attractive force equivalent to $600-800 \mathrm{~g}$ $(5.88 \mathrm{~N}-7.84 \mathrm{~N})$, which, if measured with interposed tissue, could be theoretically sufficient to create the anastomosis. However, the published study acute, and no survival study has been published so far to ascertain that a safe and robust anastomosis could be obtained with that compression force through the thickness of the gastric wall [19].

There was no significant correlation between magnetic force and burst pressure, which was greater than $110 \mathrm{mmHg}$ in all cases. However, the limited number of experiments does not allow any conclusion to be drawn on that, and optimal magnetic force will be further studied on a more refined prototype.
Global inflammation and fibrosis scores were moderate with the Modular Auto-Assembling Anastomosis System (Table 1); however, both fibrosis and inflammation were slightly higher when compared, by the same pathologist, to our previous series of porcine colorectal anastomosis performed by means of the $28 \mathrm{~mm} \mathrm{EEA}^{\mathrm{TM}}$ stapler [20], and similar to those observed with the MAGNAMOSIS ${ }^{\circledR}$ in similar conditions [18]. Inflammation is crucial in the process of anastomotic healing, and there is probably a more intense acute inflammatory response in compression systems that rapidly decrease after expulsion of the device, while it is likely to last longer in stapled anastomoses. It would be of interest to assess this issue in a long-term survival study.

There are multiple reasons to focus on the development of magnetic anastomotic devices, specifically in the digestive system. The NiTinol-based (NiTi) Compression Anastomotic Ring is effective to achieve digestive anastomosis without foreign materials left in the body [34]. However, NiTi is as expensive as mechanical staplers and adds no value in terms of surgical access. The reduced cost of magnets and the possibility of being delivered through a minimally invasive approach turn them into a very appealing alternative to both staplers and NiTi-based technologies. Over the past 10 years, several patent applications have been filed for anastomotic magnetic devices, reinforcing the perception that compression-based magnetic anastomosis is a promising market for medical hardware companies, since it can facilitate minimally invasive approaches, such as NOTES and single-port procedures.

\section{Conclusions}

The modular magnetic anastomotic system showed enormous potential to create minimally invasive digestive
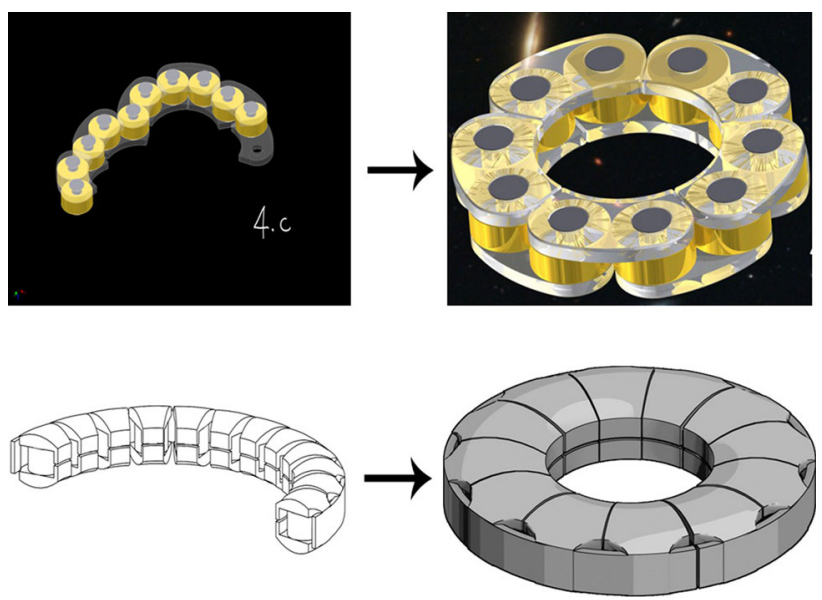

Fig. 9 Examples of upcoming industrial prototypes 
anastomoses, and may represent a valuable alternative to stapled anastomoses, being easy to deliver, safe, and effective. Low manufacturing costs may also represent additional value. The prototype requires further studies and refinements in order to define the optimal magnetic force and the most adapted delivery system (Fig. 9).

Acknowledgements The authors are grateful to Guy Temporal and Christopher Burel for proofreading the manuscript.

Disclosures Michele Diana is the recipient of a research grant from Karl Storz (Tuttlingen, Germany) and is the inventor of the modular magnetic anastomotic device. Jacques Marescaux is the recipient of grants from Karl Storz (Tuttlingen, Germany), Siemens Healthcare, and Covidien. Didier Mutter, Véronique Lindner, Michel Vix, Hyunsoo Chung, and Nicolas Demartines have no conflicts of interest or financial ties to disclose.

\section{References}

1. Costantino FA, Diana M, Wall J, Leroy J, Mutter D, Marescaux J (2012) Prospective evaluation of peritoneal fluid contamination following transabdominal vs. transanal specimen extraction in laparoscopic left-sided colorectal resections. Surg Endosc 26:1495-1500

2. Diana M, Perretta S, Wall J, Costantino FA, Leroy J, Demartines N, Marescaux J (2011) Transvaginal specimen extraction in colorectal surgery: current state of the art. Colorectal Dis 13:e104-e111

3. Diana M, Wall J, Costantino F, D'Agostino J, Leroy J, Marescaux J (2011) Transanal extraction of the specimen during laparoscopic colectomy. Colorectal Dis 13(Suppl 7):23-27

4. Leroy J, Diana M, Wall J, Costantino F, D'Agostino J, Marescaux J (2011) Laparo-endoscopic single-site (LESS) with transanal natural orifice specimen extraction (NOSE) sigmoidectomy: a new step before pure colorectal natural orifices transluminal endoscopic surgery $\left(\right.$ NOTES $\left.^{\circledR}\right)$. J Gastrointest Surg 15:14881492

5. Yamada H, Kojima K, Inokuchi M, Kawano T, Sugihara K, Nihei Z (2008) Preliminary experience using a computer-mediated flexible circular stapler in laparoscopic esophagogastrostomy. Surg Laparosc Endosc Percutan Tech 18:59-63

6. Kaidar-Person O, Rosenthal RJ, Wexner SD, Szomstein S, Person B (2008) Compression anastomosis: history and clinical considerations. Am J Surg 195:818-826

7. Aggarwal R, Darzi A (2005) Compression anastomoses revisited. J Am Coll Surg 201:965-971

8. Kopelman D, Hatoum OA, Kimmel B, Monassevitch L, Nir Y, Lelcuk S et al (2007) Compression gastrointestinal anastomosis. Expert Rev Med Devices 4:821-828

9. Hardy KJ (1990) Non-suture anastomosis: the historical development. Aust N Z J Surg 60:625-633

10. Senn N (1893) Enterorrhaphy: its history, technique, and present status. JAMA 21:215-235

11. Ho YH, Ashour MA (2010) Techniques for colorectal anastomosis. World J Gastroenterol 16:1610-1621

12. Jansen A, Keeman JN, Davies GA, Klopper PJ (1980) Early experiences with magnetic rings in resection of the distal colon. Neth J Surg 32:20-27

13. Jamshidi R, Stephenson JT, Clay JG, Pichakron KO, Harrison MR (2009) Magnamosis: magnetic compression anastomosis with comparison to suture and staple techniques. J Pediatr Surg 44:222-228

14. Pichakron KO, Jelin EB, Hirose S, Curran PF, Jamshidi R, Stephenson JT et al (2011) Magnamosis II: magnetic compression anastomosis for minimally invasive gastrojejunostomy and jejunojejunostomy. J Am Coll Surg 212:42-49

15. Gonzales KD, Douglas G, Pichakron KO, Kwiat DA, Gallardo SG, Encinas JL et al (2012) Magnamosis III: delivery of a magnetic compression anastomosis device using minimally invasive endoscopic techniques. J Pediatr Surg 47:1291-1295

16. Diana M, Wall J, Perretta S, Dallemagne B, Gonzales KD, Harrison MR et al (2011) Totally endoscopic magnetic enteral bypass by external guided rendez-vous technique. Surg Innov 18:317-320

17. Leroy J, Perretta S, Diana M, Wall J, Lindner V, Harrison M et al (2012) An original endoluminal magnetic anastomotic device allowing pure NOTES transgastric and transrectal sigmoidectomy in a porcine model: proof of concept. Surg Innov 19:109-116

18. Wall J, Diana M, Leroy J, Deruijter V, Gonzales KD, Lindner V et al (2013) MAGNAMOSIS IV: magnetic compression anastomosis for minimally invasive colorectal surgery. Endoscopy 45(8):643-648

19. Ryou M, Cantillon-Murphy P, Azagury D, Shaikh SN, Ha G, Greenwalt I et al (2011) Smart Self-Assembling MagnetS for ENdoscopy (SAMSEN) for transoral endoscopic creation of immediate gastrojejunostomy (with video). Gastrointest Endosc 73:353-359

20. Diana M, Leroy J, Wall J, De Ruijter V, Lindner V, Dhumane P et al (2012) Prospective experimental study of transrectal viscerotomy closure using transanal endoscopic suture vs. circular stapler: a step toward NOTES. Endoscopy 44:605-611

21. Dietz UA, Debus ES, Hirt AL, Czeczko NG, Malafaia O, Geiger D et al (1999) From Murphy's button to the Valtrac Ring: 100 years in search of a paradigm (in German). Zentralbl Chir 124:653-656

22. Diana M, Noll E, Diemunsch P, Dallemagne B, Benahmed MA, Agnus V et al (2013) Enhanced-reality video fluorescence: a realtime assessment of intestinal viability. Ann Surg. doi:10.1097/ SLA.0b013e31828d4ab3

23. Matthiessen P, Hallbook O, Rutegard J, Simert G, Sjodahl R (2007) Defunctioning stoma reduces symptomatic anastomotic leakage after low anterior resection of the rectum for cancer: a randomized multicenter trial. Ann Surg 246:207-214

24. Enker WE, Merchant N, Cohen AM, Lanouette NM, Swallow C, Guillem J et al (1999) Safety and efficacy of low anterior resection for rectal cancer: 681 consecutive cases from a specialty service. Ann Surg 230:544-552; discussion 552-544

25. Matthiessen P, Lindgren R, Hallbook O, Rutegard J, Sjodahl R (2010) Symptomatic anastomotic leakage diagnosed after hospital discharge following low anterior resection for rectal cancer. Colorectal Dis 12:82-87

26. Espinel J, Pinedo E (2012) Stenosis in gastric bypass: endoscopic management. World J Gastrointest Endosc 4:290-295

27. Ballantyne GH, Burke JB, Rogers G, Lampert EG, Boccia J (1985) Accelerated wound healing with stapled enteric suture lines: an experimental study comparing traditional sewing techniques and a stapling device. Ann Surg 201:360-364

28. Graffner H, Andersson L, Lowenhielm P, Walther B (1984) The healing process of anastomoses of the colon: a comparative study using single, double-layer or stapled anastomosis. Dis Colon Rectum 27:767-771

29. Lustosa SA, Matos D, Atallah AN, Castro AA (2001) Stapled versus handsewn methods for colorectal anastomosis surgery. Cochrane Database Syst Rev (3):CD003144

30. Cope C (1995) Creation of compression gastroenterostomy by means of the oral, percutaneous, or surgical introduction of 
magnets: feasibility study in swine. J Vasc Interv Radiol 6:539-545

31. Cope C, Ginsberg GG (2001) Long-term patency of experimental magnetic compression gastroenteric anastomoses achieved with covered stents. Gastrointest Endosc 53:780-784

32. Chopita N, Vaillaverde A, Cope C, Bernedo A, Martinez H, Landoni $\mathrm{N}$ et al (2005) Endoscopic gastroenteric anastomosis using magnets. Endoscopy 37:313-317
33. van Hooft JE, Vleggaar FP, Le Moine O, Bizzotto A, Voermans RP, Costamagna G et al (2010) Endoscopic magnetic gastroenteric anastomosis for palliation of malignant gastric outlet obstruction: a prospective multicenter study. Gastrointest Endosc 72:530-535

34. Masoomi H, Luo R, Mills S, Carmichael JC, Senagore AJ, Stamos MJ (2013) Compression anastomosis ring device in colorectal anastomosis: a review of 1,180 patients. Am J Surg 205:447-451 